\title{
Cerebral vasospasm and wernicke encephalopathy secondary to adult cyclic vomiting syndrome: the role of magnesium
}

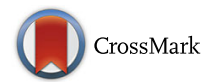

\author{
Álvaro Sánchez-Larsen ${ }^{*}$ (D), Tomás Segura', Susana García-Muñozguren², Javier Peinado-Ródenas³, \\ Joaquín Zamarro ${ }^{4}$ and Francisco Hernández-Fernández ${ }^{1,5}$
}

\begin{abstract}
Background: Magnesium has a regulatory role in the excitability of cell membranes, and is also a cofactor in the phosphorylation of thiamine. Hypomagnesemia has been associated with coronary vasospasm, but its role in cerebrovascular pathology is controversial, and cerebral vasospasm exclusively attributable to hypomagnesemia has not been reported in humans.

Case presentation: We report the case of a 51-year-old man in whom uncontrollable vomiting, treatment with omeprazole and thiazide, and renal impairment lead to a severe hypomagnesemia (magnesium below the level of detection in blood tests), which secondarily caused Wernicke's encephalopathy and vasospasm in multiple cerebral arteries (seen with cerebral angiography and CT angiography) that presented with a complete right hemisphere neurological deficit. These disturbances completely resolved when magnesium levels were normalized and subsequent neuroimaging tests confirmed the resolution of angiographic changes.
\end{abstract}

Conclusion: Our case suggests that hypomagnesemia should be considered in the differential diagnosis of patients with neurological symptoms and predisposing causes.

Keywords: Hypomagnesemia, Wernicke encephalopathy, Cerebral vasospasm, Cyclic vomiting syndrome, Case report

\section{Background}

Magnesium is the most abundant intracellular divalent cation and the fourth most abundant element in the body. The majority of this mineral is localized in the bones and soft tissues, only $1 \%$ resides in the extracellular fluids [1]. Magnesium balance is maintained by means of intestinal absorption in the small bowel, mostly in the ileum and distal part of jejunum, and renal excretion. The kidneys are crucial in magnesium homeostasis. $70 \%$ of the magnesium filtered is reabsorbed in the thick ascending limb of the loop of Henle. It is estimated that an adult needs an intake of 255-350 mg daily [1]. Conditions that can lead to hypomagnesemia include alcoholism, diabetes, malabsorption (Crohn's disease, ulcerative colitis, coeliac

\footnotetext{
* Correspondence: aa.sanchezlarsen@gmail.com

${ }^{1}$ Department of Neurology, Complejo Hospitalario Universitario de Albacete, Albacete, Spain

Full list of author information is available at the end of the article
}

disease, short bowel syndrome), gastrointestinal loses (biliary or intestinal fistula, large-volume diarrhea or vomiting) endocrine causes (hyperaldosteronism, hyperparathyroidism, syndrome of inappropriate antidiuretic hormone secretion, hypercalcemia, hypercalciuria), renal disease (renal failure, dialysis, intrinsic tubular disorders) and medication use (diuretics, proton pump inhibitors, antibiotics, chemotherapeutic agents) [1].

The principal function of magnesium in the human body is structural, mainly in bones and teeth. However, according to its ionic characteristics, it also plays a role in the regulation of the excitability of neuromuscular membranes. Magnesium works as a cofactor in many enzymatic reactions such as ATP kinase reactions or the activation of thiamine by its phosphorylation to thiamine pyrophosphate $[1,2]$. Magnesium is also an antagonist of the N-methyl-d-aspartate (NMDA) receptor [1, 3], and has direct vasodilatory effects due to various mechanisms. Hypomagnesemia is thought to lead to an 
increase in vascular smooth muscle tone and reactivity, its association with acute focal vasospasm in coronary arteries has been known for decades [4], albeit cerebral vasospasm exclusively attributable to hypomagnesemia in humans has not been reported. We report a case of vasoconstriction in multiple cerebral arteries and Wernicke's encephalopathy (WE) secondary to hypomagnesemia.

\section{Case presentation}

A 51-year-old man, diagnosed with adjustment disorder due to work problems, and hypertension without other vascular risk factors, non-smoker, no alcohol or drug consumption, treated with valsartan/hydrochlorothiazide and omeprazole. He presented with intermittent episodes of incoercible vomiting over a three month period, and was finally diagnosed with adult cyclic vomiting syndrome after an extensive study that ruled out organic origin (normal blood tests, stool test, urea breath test, abdominal CT scan and ultrasound, echoendoscopy with biopsies). The patient was admitted to hospital for prerenal kidney failure after several weeks of uncontrollable vomiting, up to 50 episodes per day. Physical examination was unremarkable except for intermittent optokinetic nystagmus. Blood tests showed creatinine $4.12 \mathrm{mg} / \mathrm{dL}$, urea $92 \mathrm{mg} / \mathrm{dL}$, creatinine clearance $15 \mathrm{~mL} / \mathrm{min} / \mathrm{S}$, albumin $4.6 \mathrm{~g} / \mathrm{dL}, \mathrm{Na} 142 \mathrm{mmol} / \mathrm{L}, \mathrm{K} 3.3 \mathrm{mmol} / \mathrm{L}, \mathrm{Cl} 90 \mathrm{mmol} / \mathrm{L}$,
Ca $7.6 \mathrm{mg} / \mathrm{dL}$ (normal 8.6-10.2), P $4 \mathrm{mg} / \mathrm{dL}$ (normal 2.64.5). Intravenous hydration and metoclopramide were started. $24 \mathrm{~h}$ later he presented with a sudden and complete right-sided cerebral hemisphere deficit (National Institute of Health Stroke Scale [NIHSS] score of 18), without seizures, fever or other clinical features, and with a blood pressure of 146/93 mmHg. Code Stroke was activated, ECG, brain CT scan and transcranial Doppler were normal and intravenous thrombolysis was decided upon. There was no improvement after $30 \mathrm{~min}$, and a CT angiography was performed (Fig. 1a-b) showing subtle narrowing of the entire right circulation, and stenoses in several branches of the right middle cerebral artery, making it impossible to rule out a distal vessel occlusion. Rescue therapy with mechanical thrombectomy was proposed, but cerebral angiography (Fig. 1c-d) showed several segments with stenosis without occlusion in multiple arteries of the right carotid circulation, so no therapeutic procedure was finally realized. There was no improvement after $24 \mathrm{~h}$, and the patient then developed a rapid progressive encephalopathy accompanied by visual hallucinations, ataxia, multidirectional nystagmus and ophthalmoparesis, symptoms in keeping with WE. Brain MRI was unremarkable (Fig. 1g-h, see also Additional files 1, 2, 3 and 4), with no ischemic areas or other abnormalities. Further complete blood tests were conducted, and magnesium
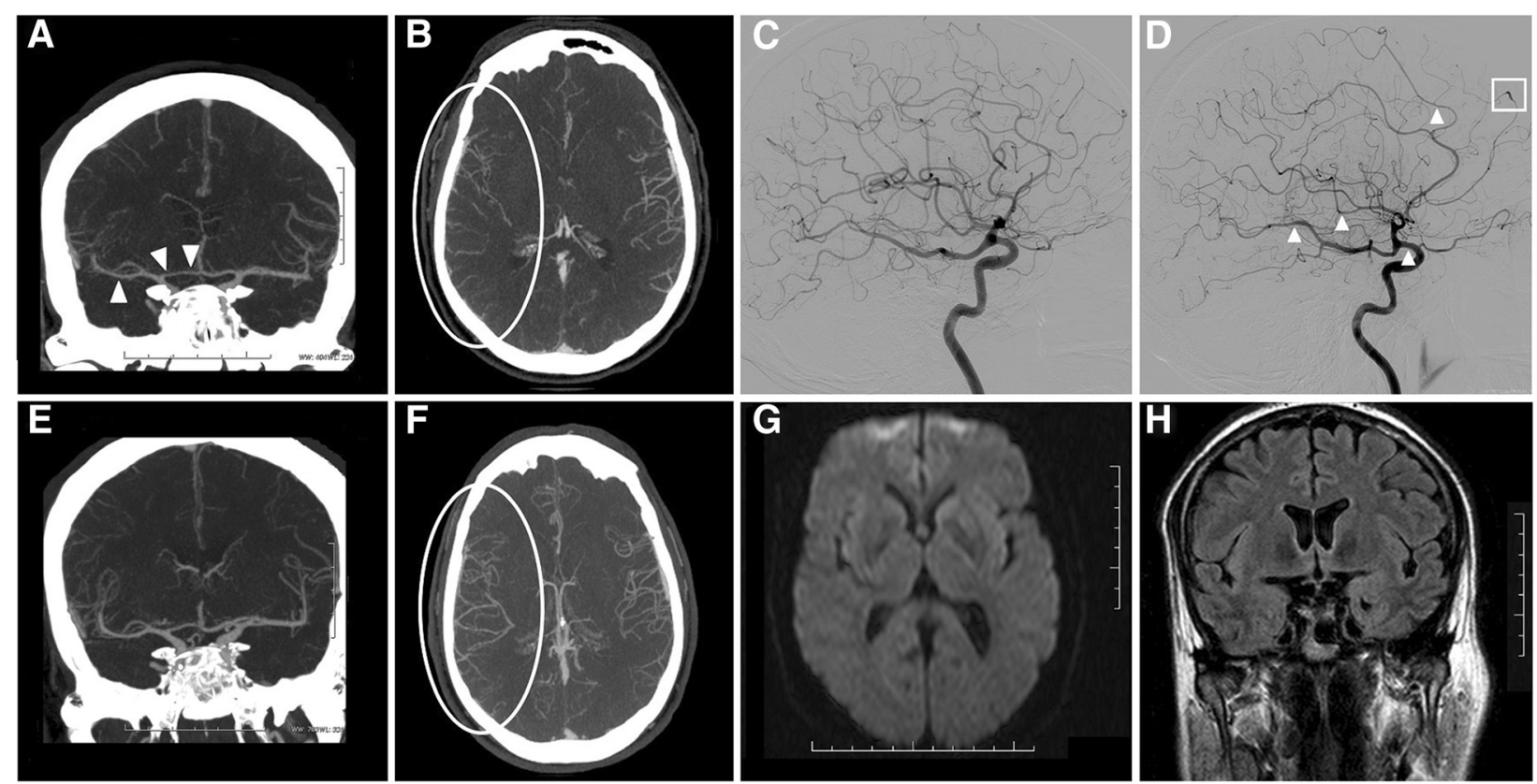

Fig. 1 Vasospasm in cerebral arteries secondary to hypomagnesemia. Coronal (a) and axial (b) CT angiography showing subtle focal changes in the vascular lumen of the right carotid circulation (a, white arrows) and overall decrease of the vascularization in the territory of the right middle cerebral artery (b, circled in white). Selective cerebral angiography injecting from the left internal carotid artery (c), without abnormalities, and from the right internal carotid artery $(\mathbf{d})$, showing overall decrease of the vascularization, focal narrowing (d, white arrows) and segmental stenosis of several arteries (d, white box). CT angiography carried out 7 days after the previous one (e and $\mathbf{f}$ ) showing complete resolution of the vascular changes. Diffusion weighted imaging (DWI) (g) and fluid attenuation inversion recovery (FLAIR) (h) sequences of brain MRI showing no relevant abnormalities 
levels were found to be below the level of detection $(<0.5 \mathrm{mg} / \mathrm{dL}$, normal 1.5-2.5), mild hypocalcaemia $(6.6 \mathrm{mg} / \mathrm{dL})$ and hypophosphatemia $(1.9 \mathrm{mg} / \mathrm{dL})$ were also observed. Diuretics, omeprazole and dextrose were stopped, intravenous ondansetron controlled the vomiting, and aggressive intravenous magnesium replacement, saline and empirical thiamine were commenced, and the patient was admitted to the intensive care unit to control potential cardiac arrhythmias. Blood tests after $24 \mathrm{~h}$ showed almost normal calcium levels $(8.5 \mathrm{mg} / \mathrm{dL})$ and a mild hypomagnesemia persisting $(1.3 \mathrm{mg} / \mathrm{dL})$. In subsequent blood tests all ions were always in normal ranges. No cardiac abnormalities were apparent, and following analytical recovery the patient started to improve and within $48 \mathrm{~h}$ the focal symptoms disappeared, and WE was completely resolved within two weeks. CT angiography carried out 7 days after the beginning of symptom onset (Fig. 1e-f) showed resolution of the arterial changes. Subsequent studies excluded renal tubular diseases (normal magnesium and other ions in 24-hour urine), endocrine disorders (PTH and 25-hydroxy vitamin D normal) and in successive neuroimaging controls no new abnormalities were found. The patient remains neurologically asymptomatic.

\section{Conclusions}

Acute hypomagnesemia can produce different symptoms depending on the severity of the deficiency. Early signs of hypomagnesemia are non-specific and include loss of appetite, lethargy, nausea, vomiting, fatigue and weakness. The association with hypophosphatemia and hypocalcaemia is frequent. Subsequently, lower magnesium levels can result in tremor, muscle cramps, tetany and generalized seizures [1]. On the other hand, chronic magnesium deficiency is not rare these days, however, it usually remains asymptomatic. This condition has been associated with anxiety, depression, other psychiatric disorders and dementia [1]. Hypomagnesemia is a known cause of Wernicke's encephalopathy, and frequently these cases are refractory to treatment with thiamine, as magnesium is a cofactor in thiamine phosphorylation, needed for its activation [2]. Our patient developed WE, without an associated Korsakoff syndrome as he did not present with amnesia. These symptoms were completely reversed after two weeks of supplementation with magnesium and thiamine.

As previously mentioned, magnesium plays a key role in the regulation of the excitability of cell membranes. It antagonizes the NMDA receptor $[1,3]$ and cell surface and intracellular voltage-gated calcium channels $[3,5]$, thereby impeding calcium entry to ischemic neurons, which is crucial for the activation of cellular apoptotic pathways. Due to these actions, magnesium has been shown to be a neuroprotective agent in different models of cerebral ischemia, demonstrating improvement of prognosis after a cardiac arrest [6], in pre-term infant hypoxic-ischemic injury [7], during cardiac by-pass surgery [8] and during carotid endarterectomy [9]. Nonetheless, recent trials that evaluated intravenous magnesium versus placebo in acute stroke have shown no benefit to this treatment, nor remarkable adverse events $[10,11]$.

According to its cardiovascular functions, magnesium deficiency has been linked to vascular risk factors such as hypertension, atherosclerosis and diabetes, as well as having a statistical association with greater risk of coronary heart disease, myocardial infarction, sudden cardiac death and stroke [1]. This ion has direct vasodilatory effects in the cerebral vasculature by antagonizing endothelin-1, neuropeptide $\mathrm{Y}$ and angiotensin II, whilst at the same time exerting a calcium antagonist effect on vascular smooth muscle $[3,5]$. Several trials reported its benefit as a vasodilator agent improving symptomatic vasospasm and delayed ischemia in aneurysmal subarachnoid hemorrhage (SAH) $[12,13]$, and for years it was used routinely in the treatment of these problems. However, recent trials evaluated the effect of intravenous magnesium for aneurysmal SAH and showed no benefit in any of their objectives [14, 15]. It is possible that prolonged delay of the administration of magnesium and its limited passage through the blood-brain barrier after intravenous supplementation $[5,16]$ have limited its potential benefit. Furthermore, hypomagnesemia has been previously described as a cause of human coronary [4, 17] and retinal [18] vasospasm, but cerebral vasospasm directly attributable to hypomagnesemia has previously been proven only in animals models [19]. This may be because cerebral circulation is less sensitive to variations in magnesium concentrations due to the blood-brain barrier, and mild or moderate hypomagnesemia may have no effect on the cerebral vasculature. In the case of our patient, massive vomiting, renal impairment and previous treatment with omeprazole and thiazide lead to a severe hypomagnesemia, which caused secondary vasoconstriction in multiple cerebral arteries, in addition to WE. These disturbances were resolved when serum magnesium levels were normalized, which further confirms the cause-and-effect relationship. It is also possible that adult cyclic vomiting syndrome, which has been associated with autonomic vascular changes [20,21], could have played a role in the cerebral vasospasm of the patient, albeit previous studies did not report any cerebrovascular event, so it is difficult to establish a clear association in this case. As to why our patient developed cerebral vasospasm and not vasospasm at other locations remains unknown. In the same way, we cannot give a feasible explanation for why these changes only occurred in the right hemisphere 
and not in both. Further studies in this area are needed to confirm these hypotheses.

In conclusion, hypomagnesemia should be considered in the differential diagnosis of patients with neurological symptoms and predisposing causes for magnesium deficit. To the best of our knowledge, we have not found any other reported cases of cerebral vasospasm attributable to hypomagnesemia in humans in the literature. This may be an underdiagnosed condition which should be considered because rapid detection and correction of serum magnesium levels would completely resolve the symptoms. Further studies are needed to confirm these hypotheses.

\section{Additional files}

Additional file 1: MRI, axial T1 sequence of the pons, cerebellum and temporal poles showing no abnormalities. (JPG $265 \mathrm{~kb}$ )

Additional file 2: MRI, axial T1 sequence of the pons, cerebellum and temporal poles showing no abnormalities. (JPG $417 \mathrm{~kb}$ )

Additional file 3: MRI, axial T1 sequence of the midbrain, perisylvian spaces and temporo-occipital regions showing no abnormalities. (JPG $395 \mathrm{~kb}$ )

Additional file 4: MRI, axial T1 sequence of the basal ganglia showing no abnormalities. (JPG $277 \mathrm{~kb}$ )

\section{Abbreviations}

NIHSS, National Institute of Health Stroke Scale; NMDA, N-methyl-d-aspartate; SAH, subarachnoid hemorrhage; WE, Wernicke's encephalopathy

\section{Acknowledgements}

The authors would like to thank the patient and his family for their cooperation and consent in relation to this study. We also want to thank the Research Committee of the Gerencia de Atención Integrada of Albacete for the support given for the publication of this article.

\section{Funding}

None funding declared

\section{Availability of data and materials}

Data of the clinical history of the patient (discharge summary, blood tests and radiological tests) will not be shared to maintain his anonymity. However, these data are available for review by the by the Editor-in-Chief of this journal.

\section{Authors' contributions}

SGM, FHF, ASL interviewed, diagnosed and treated the patient. JZ, JPR performed the radiological tests, evaluated the neuroimaging findings and gave important clinical opinions. ASL drafted the manuscript. FHF, TS participated in the design of the case report and helped to draft the manuscript. All authors read and approved the final manuscript.

\section{Competing interests}

The authors declare that they have no competing interests.

\section{Consent for publication}

Written informed consent was obtained from the patient for publication of this case report and any accompanying images. A copy of the written consent is available for review by the Editor-in-Chief of this journal. The publication of this manuscript was approved by the Clinical Research Ethics Committee of the Complejo Hospitalario Universitario de Albacete.

Ethics approval and consent to participate

Not applicable

\section{Author details}

'Department of Neurology, Complejo Hospitalario Universitario de Albacete, Albacete, Spain. ${ }^{2}$ Department of Neurology, Grupo Hospitales de Madrid, Madrid, Spain. ${ }^{3}$ Department of Radiology, Complejo Hospitalario Universitario de Albacete, Albacete, Spain. ${ }^{4}$ Unit of Interventional Neuroradiology, Department of Radiology, Hospital Universitario Virgen de la Arrixaca, Murcia, Spain. ${ }^{5}$ Unit of Interventional Neuroradiology, Department of Radiology, Complejo Hospitalario Universitario de Albacete, Albacete, Spain.

Received: 29 April 2016 Accepted: 2 August 2016

Published online: 11 August 2016

\section{References}

1. Gröber U, Schmidt J, Kisters K. Magnesium in Prevention and Therapy. Nutrients. 2015;7:8199-226.

2. Sechi G, Serra A. Wernicke's encephalopathy: new clinical settings and recent advances in diagnosis and management. Lancet Neurol. 2007:6:442-55.

3. Chang JJ, Mack WJ, Saver JL, Sanossian N. Magnesium: potential roles in neurovascular disease. Front Neurol. 2014;5:52

4. Hanline Jr M. Hypomagnesemia causes coronary artery spasm. JAMA. 1985;253:342.

5. Muir KW. Therapeutic potential of magnesium in the treatment of acute stroke. J Stroke Cerebrovasc Dis. 2000;9:257-67.

6. Longstreth Jr WT, Fahrenbruch CE, Olsufka M, Walsh TR, Copass MK, Cobb LA. Randomized clinical trial of magnesium, diazepam, or both after out-ofhospital cardiac arrest. Neurology. 2002;59:506-14.

7. Rouse DJ, Hirtz DG, Thom E, Varner MW, Spong CY, Mercer BM, et al. A randomized, controlled trial of magnesium sulfate for the prevention of cerebral palsy. N Engl J Med. 2008;359:895-905.

8. Bhudia SK, Cosgrove DM, Naugle Rl, Rajeswaran J, Lam BK, Walton E, et al. Magnesium as a neuroprotectant in cardiac surgery: a randomized clinical trial. J Thorac Cardiovasc Surg. 2006;131:853-61.

9. Mack WJ, Kellner CP, Sahlein DH, Ducruet AF, Kim GH, Mocco J, et al. Intraoperative magnesium infusion during carotid endarterectomy: a double-blind placebo-controlled trial. J Neurosurg. 2009;110:961-7.

10. Muir KW, Lees KR, Ford I, Davis S. Intravenous Magnesium Efficacy in Stroke (IMAGES) Study Investigators. Magnesium for acute stroke (Intravenous Magnesium Efficacy in Stroke trial): randomised controlled trial. Lancet. 2004;363:439-45.

11. Saver JL, Starkman S, Eckstein M, Stratton SJ, Pratt FD, Hamilton S, et al. FAST-MAG Investigators and Coordinators. Prehospital use of magnesium sulfate as neuroprotection in acute stroke. N Engl J Med. 2015:372:528-36.

12. Veyna RS, Seyfried D, Burke DG, Zimmerman C, Mlynarek M, Nichols V, et al. Magnesium sulfate therapy after aneurysmal subarachnoid hemorrhage. J Neurosurg. 2002;96:510-4.

13. Wong GK, Chan MT, Boet R, Poon WS, Gin T. Intravenous magnesium sulfate after aneurysmal subarachnoid hemorrhage: a prospective randomized pilot study. J Neurosurg Anesthesiol. 2006;18:142-8.

14. Wong GK, Poon WS, Chan MT, Boet R, Gin T, Ng SC, et al. Intravenous magnesium sulphate for aneurysmal subarachnoid hemorrhage (IMASH): a randomized, double-blinded, placebo-controlled, multicenter phase III trial. Stroke. 2010;41:921-6.

15. Dorhout Mees SM, Algra A, WP V d t, van Kooten F, Kuiisten HA, Boiten J, et al. Magnesium for aneurysmal subarachnoid haemorrhage (MASH-2): a randomized placebo-controlled trial. Lancet. 2012;380:44-9.

16. McKee JA, Brewer RP, Macy GE, Phillips-Bute B, Campbell KA, Borel CO, et al. Analysis of the brain bioavailability of peripherally administered magnesium sulfate: A study in humans with acute brain injury undergoing prolonged induced hypermagnesemia. Crit Care Med. 2005:33:661-6.

17. Minato N, Katayama $Y$, Sakaguchi M, Itoh M. Perioperative coronary artery spasm in off-pump coronary artery bypass grafting and its possible relation with perioperative hypomagnesemia. Ann Thorac Cardiovasc Surg. 2006;12:32-6.

18. Cohen L, Laor A, Kitzes R. Reversible retinal vasospasm in magnesium-treated hypertension despite no significant change in blood pressure. Magnesium. 1984;3:159-63. 
19. Seelig JM, Wei EP, Kontos HA, Choi SC, Becker DP. Effect of changes in magnesium ion concentration on cat cerebral arterioles. Am J Physiol. 1983;245:22-6.

20. Rashed H, Abell TL, Familoni BO, Cardoso S. Autonomic function in cyclic vomiting syndrome and classic migraine. Dig Dis Sci. 1999;44:74S-8S.

21. To J, Issenman RM, Kamath MV. Evaluation of neurocardiac signals in pediatric patients with cyclic vomiting syndrome through power spectral analysis of heart rate variability. J Pediatr. 1999;135:363-6.

Submit your next manuscript to BioMed Central and we will help you at every step:

- We accept pre-submission inquiries

- Our selector tool helps you to find the most relevant journal

- We provide round the clock customer support

- Convenient online submission

- Thorough peer review

- Inclusion in PubMed and all major indexing services

- Maximum visibility for your research

Submit your manuscript at www.biomedcentral.com/submit
() BioMed Central 